\title{
The Effect of Internet Usage on Relations between Members of the Omani Family in the Dhofar Region
}

\author{
Reem Abuiyada ${ }^{1}$, Salithamby Rauff ${ }^{1} \&$ Adnan Eteiwi $^{2}$ \\ ${ }^{1}$ Social Sciences Department, Dhofar University, Salalah, Sultanate of Oman \\ ${ }^{2}$ Foundation Program, Dhofar University, Salalah, Sultanate of Oman \\ Correspondence: Reem Abuiyada, Department of Social Sciences, Dhofar University, P.O Box: 2509, Postal \\ Code 211, Salalaha, Sultanate of Oman. Tel: 968-9855-1426. E-mail: reem@du.edu.om
}

Received: January 27, 2016 Accepted: February 14, 2016 Online Published: March 18, 2016

doi:10.5539/ass.v12n4p131 URL: http://dx.doi.org/10.5539/ass.v12n4p131

\begin{abstract}
Oman has a society which is highly driven by religious and cultural values. Religion and culture have both been apparent sustenance to shape every area of Omanis' daily life at individual, familial and societal levels. The instituting of modern technology, particularly the Internet, has a decisive impact on the traditional and structural nature of Omani's family life. This study has examined such impact on families. This is an exploratory study employing quantitative data. Around 200 families from different parts of Dhofar, Oman (such as Salalah, Mirbath, Thamreet and Taqa) have been recruited by a purposive sampling, and their views and experiences on how their use of modern technology influences their life were collected. The findings suggested that the Internet use has produced a low husband-wife relationship in family life. Findings also suggest that there was a low relationship between siblings in a family. The Internet use had also effects on Omani families' traditional culture and beliefs.
\end{abstract}

Keywords: internet usage, Oman, family, relationships, children

\section{Introduction}

Societies in the Arabian Gulf have been undergoing radical changes in various aspects of people's lives. Families are passing through a rapid transition that affects functions and relationships among members. The Sultanate of Oman, the second-largest country on the Arabian Gulf has also deeply affected by the rapid changes in the area.

The Internet is a powerful tool that has shaped the performance of various fields including communication, business, politics, and education. There is no doubt that the Internet is virtually everywhere and has dramatically altered the way we live. It is rapidly growing not only in the industrialized countries but also in the developing world. As a result, the role of the Internet in our daily lives has expanded rapidly to the degree that many of us have become dependent on it, if not addicted to (Katz, 2002). As is the case elsewhere in the world, the use of the Internet has become an important element of life in the Sultanate of Oman, opening doors to allow people to interact freely. While any technology can be put to good or bad use depending on the user, many Omani families use their computers for multiple purposes in an effort to search out materials they need or are interested in without major challenges. Because relationships among family members are essential to the maintenance of kinship family ties and reflect respect, compassion, and love, it will become increasingly important to re-examine the impact of the Internet usage on Omani families. This study delves into the effect of Internet usage on the family relationships in the Sultanate of Oman, focusing on relationships between spouses, parents, children, and between the children themselves.

\subsection{The Statement of the Problem}

The family is a dynamic social system that has structure, functions, roles and authority patterns. The way the system operates and adapts to change affects the relationships within it, and it is affected by external and internal factors. The Internet is one of several important factors that affect relationships among the family members. Hence, this study attempts to highlight this new technology that has entered most households in order to study the effect of Internet usage on relationships among the members of Omani families. 


\subsection{The Aim of the Study}

This study aims to study the effect of Internet usage on relationships among the members of Omani families, including relations between spouses, their children, and the children themselves. It also will provide through recommendations optimal way to deal with this new technology.

\subsection{Objectives}

This study will determine the effect of Internet usage on the family relationships, family's budget and children's educational achievement, incorporating its positive and negative effects, religiously, morally, and socially. This can be done through the recognition of certain social and economical characteristics of the research group, studying the nature of Internet usage in Omani families' place, time, period of usage, within individual or collective applications, reasons of usage, and most-visited websites on the net, identifying the level of organizing the internet's usage and the amount of monitoring imposed by the user and members of his family.

\subsection{Research Questions}

The study has the following three research questions to derive answers to satisfy its objectives

1. What is the nature of using internet by members of family?

2. What are the effects of internet usage in shaping relations of members of family?

3. What are the effects of internet usages on other areas of daily life of family members?

\section{Review of Literature}

The family is a social system that has "a collective identity," which is the "result of shared recollections of togetherness that are created as family members spend time together in shared meals, games, and chatting" (Mesch, 2006, p. 123). Communication is "a symbolic, transactional process or the process of creating and sharing meanings" (Smith et al., 2009, p. 79) and it plays a significant role in the relationship between individuals for the functioning of a family or a household. Families that spend time together "in common activities enjoy a higher quality of communication" (Mesch, 2006, p. 124). Family communication is essential to any family and household as it "plays a significant role in the relationship between family leisure and family functioning" (Smith et al., 2009, p. 80).

The internet is a new form of online interaction that enhances "offline relationships" (Wellman et al., 2001). Furthermore, DiMaggio et al. (2001) found that the internet is a way of increasing "interaction with family members and closeness to friends." In saying this, however, the frequency of daily internet use by adolescents plays a vital role in "the quality of their relationships with parents and friends" (Mesch, 2006). Mesch (2006) found that adolescents who have low internet usage had "better relationships with parents and friends than was high Internet use."

A great number of studies on the Internet Usage have handled and recycled factors of like time and age. Studies of (Howard, Raine, \& Jones, 2001) and (Orleans \& Laney, 2000) analyzed such factors respectively. The Social context and how its variables impacts family relations have been seldom.

Family life with an eye to the Internet use over a two-year period was screened by (Kraut, Mukhopadhyay, Szczypula, Kiesler, \& Scherlis, 2000). It was found that interaction was the main purpose both mothers and fathers and their children opted for. This had happened less often before the people had the facility available at home. Although the outcome might show an impact on familial relationships but in a subsequent study, this concern didn't continue to persist (Kraut et al., 1998).

In another study of Orleans and Laney (2000), at the age of 8-17, 32 children were observed with their parents. They scarcely communicated as they used their computers three times with sessions of no less than one hour time. Children communicated together in as much as $65 \%$ of the time they went online. Different sexes used the computers differently: females used the computer instrumentally while use by males was more integrative (Orleans \& Laney, 2000, p. 67).

In a study by Livingstone (2002), it was found that only $6 \%$ of parents were concerned with their children's use of computers and the Internet. Parents were far more concerned with other concerns and standards. Findings show that parents were more concerned with other threats to their children well-being than with computer and Internet use, $6 \%$. But around $50 \%$ of the parents were reported to have rules as for the Internet use. Differently, children have only around half that of restrictions. This signifies the necessity for closer observation and data to explain the behavior of both parties inside the households.

The contextual nature of parents' Internet concerns compared with their concerns with other aspects of life 
illustrates the importance of studying the Internet in context to provide a more complete understanding of how the technology fits with other aspects of family life. When the Internet is studied in isolation, it is easy to misunderstand how it fits with other aspects of family life and might distort its significance and influence. These studies provide a glimpse into the variety of ways that the Internet may affect relationships in families. Whether they have a positive or negative impact on family interactions is a complicated question that requires more research and the consideration of what and how household technologies, namely, the Internet might do that to issues such as family communication, and socialization in general.

Social actualities of family life lend themselves to having better understanding of whether or not the Internet use can have any impact on family relations, and if any, whether similar impact(s) have certain trends and if they influence family communication and socialization in general.

Another important research trend is whether this facility can help family members; communication between members, distant or inbound members, older generations, social problems such as divorce, doing office work or even household education.

It's time to start to explore questions relevant to household relationships like maintaining relationships with distant and inbound family members, doing family work and education for a better understanding of modern family socialization. It is time to consider the ways family members employ the Internet in all family affairs.

New Internet users seem to confirm that the Internet might be relevant to withdrawal from socialization (Kraut et al., 1998). This actuality returned to normal after a period of 2-3 years of use.

In another study with a different sample, the same researchers added more variables and wider spectrum of social measures. This time, findings showed that the number of close and distant social contacts as well as the in-person communication with family and friends increased. The result fostered the assumption that the facility had a positive impact on the maintenance of social networks.

In support of this, other researchers have concluded that the Internet does maintain social relations Internet users at home were reported to use it for friend and family communication. Moreover, and in another study, interpersonal relationships were reported to be the why behind sending and receiving e-mail messages (Stafford, Kline, \& Dimmick, 1999). The number of those who used this facility for this end was twice as many as those who used it for business or information. Franzen (2000) reported social relations better maintained due to the same application. Nearly two thirds had more friend and family communication once they had their e-mails functioning (Howard et al., 2001). The Internet fostered familial communication (Fox at al., 2001).

Overall, these findings suggest that the Internet has positive effects on family members' ability to maintain socialization outside the parameter of people's own families.

\section{Methodology}

This is an exploratory study that embarked quantitative data. To garner rich data, meet its research objectives and answer its research questions viably, this research design is essential for this study. The basic aspects pertaining to the methodology of this study are: research population, research area, sampling, data collection and data analysis, as described in this chapter.

\subsection{Research Population}

The research population of this study is families living in the Dhofar region of Oman. These families are structure in a basically tradition manner. However, they are today increasingly becoming users of modern technology to fulfil their needs. This use of technology has been apparently impacting their oldest traditional family life today in the region.

\subsection{Rational for Selection of Research Area}

Dhofar is one major region in Oman. Relatively, families living in this region are highly conventional and their daily life has been more driven by traditional socio-economic factors and values. Today, the arrival of information technology, including internet, has become a noticeable social phenomenon to influence virtually every area of life of people (families) in this region. And families in the region are also steadily recognising the importance of modern technology in their familial life. This fact led the researchers of this study to opt the Dhofar as research area for the study.

\subsection{Sampling}

Some two hundred (200) families were including in this study. They were recruited from Salalah, Mirbath, Thamreet and Taqa. A purposive sampling was employed to recruit them. Apart from this, separate recruitment 
criteria were also applied during their selection. The criteria were (i) one or both members of a spouses unit (husband or wife) must use the Internet and (ii) at least one of their children (if they had any) must also use the Internet.

\subsection{Rational for Sample}

The researchers found that the purposive sampling was sufficiently viable for this study. This is because this sampling was widely recognized in social sciences as a most efficient tool to derive reliable and rich data and articulate the real picture and gravity of any issue/phenomenon in the society (Dolores \& Tongco, 2007).

\subsection{Data Collection}

Data were collected from all 200 participants in the study by questionnaires. Three types of questionnaires were set by the researchers themselves. Type 1 was for the husband, Type 2 for the wife and Type 3 for the children. All three types of questionnaires were distributed to respective participants and data was collected. Participants were asked to freely share their experience of Internet usage in daily life. Type 1 questionnaires found 178 of 200 husbands to be Internet users. Type 2 questionnaires showed that 133 of 200 wives were Internet users. Meanwhile, Type 3 questionnaires suggested that out of 200 children in families, 187 were serious internet users.

\subsection{Data Analysis}

The data were analysed with a computer-guided analytical system. The Statistical Package of Social Science (SPSS) program was applied to ensure descriptive statistics (such as arithmetic mean, standard deviation, frequency distribution and percentages as a method to display basic variables. Apart from this, Berelson's coefficient of correlation and Chi-square test were also applied to present, manage, and protect data in the study.

\section{Findings and Discussion}

The findings of the study were split into five major categories based data derived from all participants. They include: socio-economic demographic characteristics of participants, the nature of Internet usage, the Internet's influence on families, advantages and disadvantages of Internet usage on families and the statistical correlation between the research variables

\subsection{Social and Economical Characteristics of the Research Group}

- $54.5 \%$ of the fathers were between the ages of $40-50$, and $45.5 \%$ of mothers were between the ages of 30 -40 . Children were aged between 15 and 20 they represented $42 \%$ of the total participants.

- Regarding the education status of participants, $52 \%$ of fathers, $49 \%$ of mothers, and $47.7 \%$ of children were holders of a degree.

- Among participants, $65 \%$ of fathers and $48.5 \%$ of mothers were public employees.

- Regarding their income level, $31 \%$ of families had a monthly income of RO 1,000-1,500, while $39 \%$ of them received above RO 1,500 monthly.

\subsection{The Data Related to the Internet}

- $78.5 \%$ of families had at least one computer connected to the Internet. All families had a unique place for the computer in their homes.

- $92.1 \%$ of fathers, $98.5 \%$ of mothers, and $97.9 \%$ of children listed the home as their prime Internet access point.

- $\quad 35.4 \%$ of fathers, $18 \%$ of mothers, and $32.6 \%$ of children had a private computer connected to the Internet. Meanwhile, the findings showed that $78.6 \%$ of fathers, $85.7 \%$ of mothers, and $80.3 \%$ of children used the Internet in the company of others.

- The findings suggested $77.5 \%$ of fathers, $88 \%$ of mothers, and $68.4 \%$ of children used the Internet 3 hours per a day, while the usage among $73.6 \%$ of fathers, $75.2 \%$ of mothers, and $75.9 \%$ of children was unspecified period of time.

- Findings also indicated that most respondents just surf the web, jumping from one page to another. Using e-mail came next. It became clear that the primary reason for the Internet usage was entertainment, and second education. The most visited web sites by our research group were news sites, following online forums.

- According to findings, half of families were organizing the usage of the Internet and monitor the user enough. 


\subsection{Influence of the Internet on the Family}

Findings suggested:

- $92.4 \%$ of husbands reported low relations with their wives and this inadequate relation was experienced by $69.1 \%$ of wives with their husbands. Meanwhile, $6.8 \%$ of husbands and $23.6 \%$ of wives felt that the influence of the internet is average. And on the other side, $0.7 \%$ of husbands and $7.3 \%$ of wives thought that the influence was high.

- When it comes to parents child relations, the report from $78.6 \%$ of the parents and $89.8 \%$ of children was that the Internet had not influenced their relationships in any way. However, $17.1 \%$ of the parents and $8.9 \%$ of children felt its influence to be significant. Findings showed that a low percentage of subjects felt the Internet impacted the relationships between the parents and children, with just $4.2 \%$ of parents and $1.12 \%$ of children responding in this manner.

- For the relationships between children and the family, $84.8 \%$ of children responded that the Internet's effect on their relationships with siblings was low. Meanwhile, $12.4 \%$ of them felt that the effect was average. A high level of Internet was reported among just $2.7 \%$ of them.

- Financially, $39 \%$ of husbands, $38.5 \%$ of wives, and $44.5 \%$ of children felt that Internet usage had no effect on the family budget.

- For the impact of Internet usage on their children's education, $67.9 \%$ of fathers, and $63.1 \%$ of mothers found neither positive nor negative influence.

\subsection{Advantages and Disadvantages of the Internet}

\subsubsection{Advantages}

Findings of the study showed that the internet granted better access to educational information. However, such information was mostly unrelated to curriculum. Many of the respondents claimed the Internet provided them with good opportunities to interact with other people around the world who have the same interest of communicating. Respondents also stated that the internet was a vehicle for them to purchase what they wanted and sell what they had. It was, according to respondents, serving them to acquire further knowledge on multiple aspects in their daily life, such as religion, culture, tourism, important locations, and different people around the world. For respondents, the Internet has been a powerful tool to disseminate important information and circulate different media news and reports on every area of life. Most respondents completely agreed that the internet gives its users the ability to find information without any supervision.

\subsubsection{Disadvantages}

About half of the respondents (46\% husbands, $49 \%$ wives, and $52.5 \%$ children) complained that the Internet was being used to access unpopular or unethical things like pornography. Another half of respondents $(55.5 \%$ husbands, $63.5 \%$ wives, and $67 \%$ children) on the other hand reported that some people employ the Internet to have relations with the opposite sex. In both cases, the percentages are comparatively high in a society which is driven by religious values, beliefs, social norms, and people's behaviours.

A relatively high number of respondents viewed the Internet as influencing Omani society's religious values and ethical principles negatively. According to a considerable number of respondents $(24.7 \%$ husbands, $15.8 \%$ wives, and $35.8 \%$ children), the Internet use was discouraging people from performing their religious obligation on time. For example, as a result of Internet use, people were forgoing their prayers at their local mosque, which is an obligation in Islam.

\subsection{The Statistical Correlation between the Research Variables}

Although studying the relations between some independent variables and the effect of Internet usage on family relations as dependent variables, the findings showed:

- There was a spiritual correlated relation between the sex of the couple and the effect of Internet usage on the relationship.

- There was a correlation between the period of time the husbands spend online and the effect of Internet usage on the relationship between the couple.

- There was a correlation relation between the period of time children spend online and the effect of Internet usage on relations between parents and children from the parents' point of view. 
- There was an inverse correlation between the level organizing the usage of the Internet and the amount of monitoring imposed on the children and the effect of using the Internet on the relationship between the parents and the children from the parents' point of view.

Through investigating the relation between some independent variables and the period of time spent online as dependant variables, results show:

- There was a correlation between the users' sex and the period of time they spend on line.

- b) There is an inverse correlation between the age of fathers and mothers and the period of time they spend online.

- There was a direct correlation between the children's age and the time they spent on line.

- There was an inverse correlation between fathers' educational level and the period of time they spend online.

- e) There was a direct correlation between children's educational statuses and the period of time they spend online.

- There was a direct correlation between the family's monthly income and the period of time the fathers spent online.

- There was a direct correlation between the level organizing the usage of the Internet and the amount of monitoring imposed on the children and the period of time they spend online.

By studying the correlations between the family's monthly income as an independent variable and the level of organizing the usage of the Internet and the amount of imposed monitoring as a dependent variable, the following result emerged:

- There was an inverse correlation between the family's monthly income and the level of organizing the children's usage of the Internet and the amount of monitoring imposed on them.

\section{Conclusion}

Since the emergence of the Internet, the effect of the Internet for Omanis has become apparent. This study reveals some of the effects of Internet usage on relations between members of the Omani family, focusing on relationships between spouses, parents, children, and between the children themselves.

Overall, findings from the study show that half of the families had at least one computer connected to the Internet.

Findings also indicated that most respondents just surf the web, jumping from one page to another. Using e-mail came next. It became clear that the primary reason for the Internet usage was entertainment, and second education. The most visited web sites by our research group were news sites, following online forums.

Findings of the study showed that the internet granted better access to educational information. However, such information was mostly unrelated to curriculum. The respondents claimed the Internet provided them with good opportunities to interact with other people around the world who have the same interest of communicating. Respondents also stated that the internet was a vehicle for them to purchase what they wanted and sell what they had. It was, according to respondents, serving them to acquire further knowledge on multiple aspects in their daily life, such as religion, culture, tourism, important locations, and different people around the world. For respondents, the Internet has been a powerful tool to disseminate important information and circulate different media news and reports on every area of life. Most respondents completely agreed that the internet gives its users the ability to find information without any supervision.

About half of the respondents complained that the Internet was being used to access unpopular or unethical things like pornography. Another half of respondents on the other hand reported that some people employ the Internet to have relations with the opposite sex. In both cases, the percentages are comparatively high in a society which is driven by religious values, beliefs, social norms, and people's behaviours.

A relatively high number of respondents viewed the Internet as influencing Omani society's religious values and ethical principles negatively. According to a considerable number of respondents, the Internet use was discouraging people from performing their religious obligation on time.

\section{References}

DiMaggio, P., Hargittai, E., Neuman, W. R., \& Robinson, J. P. (2001). Social Implications of the Internet. Annual Review of Sociology. 
Dolores, M., \& Tongco, C. (2007). Purposive sampling as a tool for informant selection. Ethnobotany Rsearch \& Applications, 5, 147-158.

Fox, S., Rainie, L., Larsen, E., Horrigan, J., Lenhart, A., Spooner, T., \& Carter, C. (2001). Wired seniors: A fervent few, inspired by family ties. Washington, DC: Pew Internet \& American Life project. Retrieved June 30, 2015, from http://www.pewinternet.org/report/pdfs/PIP_Wired_Seniors_Report.pdf

Franzen, A. (2000). Does the Internet make us lonely? European Sociological Review, 16, 427-438.

Howard, P. E. N., Raine, L., \& Jones, S. (2001). Days and nights on the Internet: The impact of a diffusing technology. American Behavioral Scientist, 45, 383-404.

Katz, J. E., \& Rice, R. E. (2002). Social Consequences of Internet use: Access, involvement, and interaction. Cambridge, MA: MIT Press.

Kraut, R., Kiesler, S., Boneva, B., Cummings, J., Helgeson, V., \& Crawford, A. (2002). Internet paradox revisited. Journal of Social Issues, 58, 49-74.

Kraut, R., Mukophadhyay, T., Szczypula, J., Kiesler, S., \& Scherlis, W. (2000). Information and communication: Alternative uses of the Internet in households. Information Systems Research, 10, 287-303.

Kraut, R., Patterson, M, Lundmark, V., Kiesler, S., Mukophadhyay, T., \& Scherlis, W. (1998). Internet paradox: A social technology that reduces social involvement and psychological well-being. American Psychologist, 53, 1017-1031.

Livingstone, S. (2002). Young people and new media. Thousand Oaks, CA: Sage.

Mesch, G. S. (2006). Family Relations and the Internet: Exploring a Family Boundaries Approach. The Journal of Family Location. Retrieved from http://web.ebscohost.com.jproxy.nuim.ie/ehost/pdfviewer/pdfviewer?si $\mathrm{d}=\mathrm{b} 66230 \mathrm{f0}$-ad5d-4aed-ad99-f81 f0129aa0c\%40sessionmgr 104\&vid=4\&hid=110

Orleans, M., \& Laney, M. C. (2000). Children's computer uses in the home: Isolation or sociation? Social Science Computer Review, 18, 56-72.

Smith, K. M., Freeman, P. A., \& Zabriskie, R. B. (2009). An Examination of Family Communication within the Core and Balance Model of Family Leisure Functioning. Family Relations. Retrieved from http://onlinelibrary.wiley.com/doi/10.1111/j.1741-3729.2008.00536.x/pdf

Stafford, L., Kline, S. L., \& Dimmick, J. (1999). Home e-mail: Relational maintenance and gratification opportunities. Journal of Broadcasting and Electronic Media, 43, 659-669.

\section{Copyrights}

Copyright for this article is retained by the author(s), with first publication rights granted to the journal.

This is an open-access article distributed under the terms and conditions of the Creative Commons Attribution license (http://creativecommons.org/licenses/by/3.0/). 